\title{
Rosuvastatin induced gynecomastia: a rare presentation of newer statin
}

\author{
Suman Ruhela ${ }^{1}$, Manish Ruhela ${ }^{2 *}$, Rakesh Kumar Ola², Mahesh Rao ${ }^{3}$
}

${ }^{1}$ Medical Officer, SK Medical College and Hospital, Sikar, Rajasthan, India
${ }^{2}$ Department of Cardiology, Noble Care Hospital, Sikar, Rajasthan, India
${ }^{3}$ Department of General Surgery, Noble Care Hospital, Sikar, Rajasthan, India

Received: 16 September 2020

Accepted: 12 October 2020

\author{
*Correspondence: \\ Dr. Manish Ruhela, \\ Email: dr.manishruhela@gmail.com
}

Copyright: () the author(s), publisher and licensee Medip Academy. This is an open-access article distributed under the terms of the Creative Commons Attribution Non-Commercial License, which permits unrestricted non-commercial use, distribution, and reproduction in any medium, provided the original work is properly cited.

\begin{abstract}
Gynecomastia is a common benign disease characterized by the progressive enlargement of the glandular tissue of the male breast. The etiology may vary and may be physiological, pharmacological, pathological, or even idiopathic. Among men, drug induced gynecomastia may account for 10-20\% of cases. Several case reports have associated this condition to the use of statins. However, there are few case reports of rosuvastatin induced gynecomastia have been reported in literature. We describe a 45-year-old male who developed bilateral gynecomastia after one month of rosuvastatin therapy, after switching to a different or less potent statin (atorvastatin), his symptoms resolved with-in one month. Use of the Naranjo adverse drug reaction probability scale indicated a possible relationship between the patient's development of gynecomastia and rosuvastatin therapy.
\end{abstract}

Keywords: Rosuvastatin, Gynecomastia, Naranjo scale

\section{INTRODUCTION}

Gynecomastia is a common clinical condition characterized by benign progressive enlargement of the male breast. In most cases it is usually an asymptomatic unilateral or bilateral, tender mass beneath the areolar region. ${ }^{1}$ It may be due to an imbalance between free estrogen and androgen activities into breast, and this imbalance may be due to multiple mechanisms. ${ }^{2}$ Drug induced gynecomastia may account for $10 \%-20 \%$ of cases in men. ${ }^{3,4}$ However only few cases of rosuvastatin induced gynecomastia have been reported in the literature. ${ }^{5}$

\section{CASE REPORT}

A 45-year-old male, with a history of coronary artery disease and unstable angina had been taking aspirin 150 $\mathrm{mg} /$ day and atorvastatin $20 \mathrm{mg}$ /day for last 2 years, with suboptimal control of hypercholesterolemia. The patient's family physician advised him to switch from atorvastatin to more potent statin rosuvastatin $20 \mathrm{mg} /$ day. One month after starting the new statin, the patient gradually developed bilateral gynecomastia with enlargement and tenderness of the mammary gland. A mass extended concentrically from the nipple and was rubbery on palpation.

His body mass index (BMI) was within normal limit, and he had no history of alcohol abuse or illicit drug use. He denied use of digitalis glycosides, food supplements, or herbal remedies. Results of thyroid, hepatic and renal function tests were unremarkable, and physical examination revealed no differences in the proportions of the breasts and patient had no signs of chronic heart failure and liver failure. Because rosuvastatin was the only new drug added to the patient's pharmacologic therapy. We decided to discontinue the drug. The patient's pain rapidly resolved, and about 2 month later, the shape, size and consistency of the mammary gland had substantially improved. Therapy was restarted with atorvastatin 20 $\mathrm{mg} / \mathrm{day}$, titrated to $40 \mathrm{mg} / \mathrm{day}$, and he remained asymptomatic. 


\section{DISCUSSION}

Gynecomastia may be induced by several different mechanisms, such as increased direct estrogen activity, increased estrogen secretion, decreased testosterone production, conversion of exogenous androgens in to estrogenic compounds. ${ }^{5}$ However in many cases, the mechanism is unknown, although it is generally attributed to drugs, adrenal or testicular neoplasia, Klinefelter's syndrome, thyrotoxicosis, chronic kidney disease or liver disease, primary hypogonadism, malnutrition, Human immunodeficiency syndrome (HIV), or aging. ${ }^{2,6,7}$ Drug induced gynecomastia may be due to an impaired balance in the serum estrogen: androgen ratio, with a direct effect on the breast tissue. Another potential cause is increased secretion of prolactin from the pituitary gland, with a blockade of dopaminergic activity on lactotrope cell groups, as dopamine is the prolactin inhibiting factor in the anterior pituitary. Drugs most often implicated in causing gynecomastia are sex hormones, anti-androgens, spironolactone, cimetidine, verapamil, imatinib mesylate, finasteride, and alkylating agents, less frequently diazepam, tricyclic antidepressants, certain antipsychotics, calcium channel blockers, captopril, digitalis glycosides, omeprazole, some antibiotics, and growth hormone may cause gynecomastia, although their mechanism are not fully elucidated. ${ }^{8}$ The adverse drug reactions database of the World Health Organization (WHO) contains many reports of gynecomastia associated with statins, rosuvastatin was the last of these statins to be marketed. ${ }^{9}$ Statins could induce gynecomastia by supressing cholesterol synthesis, leading to an inhibition of adrenal or gonadal steroid production. ${ }^{10-12}$ This effect may result in an altered estradiaol: testosterone ratio. Our patient had been treated with atorvastatin since last 2 years without experiencing any signs of gynecomastia. However, one month after switching to rosuvastatin, he developed gynecomastia, moreover his symptoms resolved after rosuvastatin was discontinued. Use of Naranjo adverse drug reaction probability scale indicated a possible relationship between the patient's development of gynecomastia and rosuvastatin therapy. Atorvastatin and rosuvastatin are thought to be inhibit steroidogenesis more strongly than other statins because of their relatively potent lipid lowering effects..$^{13}$ In particular, rosuvastatin showed the highest efficacy in reducing Low density lipoprotein (LDL) cholesterol. ${ }^{14}$ This effect might explain why our patient developed gynecomastia occurred after therapy was switched from atorvastatin to rosuvastatin and why it didn't recur after atorvastatin was reintroduced. The difference between the statins in terms of adverse reactions may be due to high $20 \mathrm{mg} /$ day starting dose of rosuvastatin in contrast to recommendations which suggests a starting dose of $10 \mathrm{mg} /$ day for the first 4 weeks. ${ }^{15}$

\section{CONCLUSION}

Clinicians should be aware of the possibility of gynecomastia and other adverse endocrinal reactions when statins are prescribed, including newer agents such as rosuvastatin. In particular, when switching therapies in stable patient, clinicians should consider the risk of adverse reactions to the new drug in the absence of definite benefits.

\section{Funding: No funding sources \\ Conflict of interest: None declared \\ Ethical approval: Not required}

\section{REFERENCES}

1. Carlson HE. Gynecomastia. N Engl J Med. 1980;303:795-99.

2. Braunstein GD. Clinical practice. Gynecomastia. N Engl J Med. 2007;357:1229-37.

3. Neuman JE. Evaluation and treatment of gynecomastia. Am Fam Physician. 1997;55:1835-44, 1849-50.

4. Bowman JD, Kim H, Bustamante JJ. Drug-induced gynecomastia. Pharmacotherap. 2012;32:1123-40.

5. Roberto G, Biagi C, Montanaro N, Koci A, Moretti U, Motola D. Statin-associated gynecomastia: evidence coming from the Italian spontaneous ADR reporting database and literature. Eur J Clin Pharmacol. 2012;68:1007-11.

6. Smals AG. Gynecomastia. Neth J Med. 1987;31:4751.

7. Peyriere H, Mauboussin JM, Rouanet I. Report of gynecomastia in five male patients during antiretroviral therapy for HIV infection. AIDS. 1999;13:2167-9.

8. Hugues FC, Gourlot C, Le Jeunne C. Drug -induced gynecomastia. Ann Med Interne (Paris). 2000;151:107.

9. Uppsala Monitoring Centre. Vigibase online: the World Health Organization's adverse drug reaction database. http://www.who-umc.org. Accessed on 2 August, 2007.

10. Pfizer Ireland Pharmaceuticals. Lipitor (atorvastatin) package insert. Dublin, Ireland. 2004.

11. Novartis Pharmaceuticals Corporation. Lescol (fluvastatin) package insert. East Hanover, NJ. 2003.

12. Merck \& Co., Inc. Mevacor (lovastatin) package insert. Whitehouse Station, NJ. 2005.

13. Hammons KB, Edwards RF, Rice WY. Golfinhibiting gynecomastia associated with atorvastatin therapy. Pharmacotherap. 2006;26:1165-8.

14. Rosenson RS. Rosuvastatin: a new inhibitor of HMGCoA reductase for the treatment of dyslipidemia. Expert Rev Cardiovasc Ther. 2003;1:495-50.

15. Astrazeneca SpA. Crestor (rosuvastatin) package insert. Basiglio, Italy. 2004.

Cite this article as: Ruhela S, Ruhela M, Ola RK, Rao M. Rosuvastatin induced gynecomastia: a rare presentation of newer statin. Int J Basic Clin Pharmacol 2020;9:1744-5. 